\title{
Uma semana em Madrid: Rural e Capital
}

Gustavo Gusso*

\section{RESUMO}

Relato de uma experiência vivida por um médico de família e comunidade brasileiro com um médico rural espanhol, chamado Juan Gérvas, que tem uma produção científica bastante ampla, bem como posições muito céticas em relação à indústria farmacêutica e ao excesso de prevenção praticado na atenção primária. O personagem deste relato tem atuado para desmistificar, dentre outras questões, o falso perigo da gripe A (H1N1).

Palavras Chave: Medicina Rural; Medicina de Família; Prevenção; Atenção Primária à Saúde.

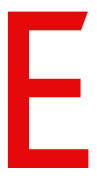

ntre os dias 11 e 17 de outubro de 2009 pude acompanhar Juan Javier Gérvas Camacho, médico geral e rural. Foi uma experiência única cujas principais impressões pretendo relatar aqui para que sigam vivas.

Cheguei a Madrid no domingo 11 de Outubro, pela TAP, via Lisboa, e Juan me esperava no aeroporto de Barajas. Me levou a Buitrago de Lozoya (75 km ao norte da cidade de Madrid, na Sierra de Guadarrama) ao hotel, e imediatamente a jantar na sua casa, de pouco mais de $100 \mathrm{~m}^{2}$, onde estava a lareira acesa. Foi surpreendente conhecer seu «local de trabalho», a simples mesa redonda com cinzeiro sobre a qual coloca seu computador portátil, que guarda no chão em um canto junto aos dois ou três documentos que necessita trabalhar neste momento; não tem escritório nem mesa própria de trabalho em casa (esta mesma mesa é usada para o jantar com sua esposa, Mercedes), e sua produção científica é inesgotável! Sim, claro, ele tem wi-fi em casa.

Juan é médico de povoados que ficam ao redor de Buitrago de Lozoya há 10 anos. Antes tinha atuado por 20 anos em Madrid. O dia 12 de outubro era feriado nacional e fomos a festas de El Cuadrón, um dos povoados que ele atende. Nestas festas costumam cozinhar comidas típicas da região em grandes panelas na rua e depois há um almoço coletivo. Chama a atenção a boa relação que Juan tem com os alcaldes (prefeitos) e pro-

*Médico de Família e Comunidade. Presidente da Sociedade Brasileira de Medicina de Familiar e Comunidade (SBMFC). fessores dos povoados aos quais serve. A região é pobre, com muitos emigrantes do leste europeu (especialmente Bulgária e Romênia) sendo que as principais atividades são a criação de gado, a silvicultura e o turismo. Na festa de El Quadrón, Dr. Juan encontrou o alcalde de Garganta e conversou sobre várias coisas do «pueblo»e de sua aposentadoria próxima. Depois da festa fomos a El Paular, o antigo «poder» do vale do Rio Lozoya, um monastério do século XIV e XV, que inclui a residência dos padres, a igreja e o palácio real (hoje um hotel). A igreja espanhola perdeu grande parte de seu patrimônio em meados do século XIX (com a desamortização de Mendizábal).

No dia seguinte à tarde (depois do trabalho), Juan foi convidado para a festa de Canencia de la Sierra, um povoado também bucólico com uma área preservada muito bonita onde há alguns anos um investidor tentou construir um condomínio privado e chegou a fazer a piscina e a estrutura de uma das casas, mas foi impedido pelo governo.

São três os povoados que Juan atua como único médico: Canencia de La Sierra, Garganta de Los Montes e El Quadrón. O maior (Canencia) tem 650 habitantes enquanto que o menor (El Quadron) por volta de 20. Durante os meses de verão e férias escolares, a população de cada vilarejo se multiplica por três. Ele vai alguns dias por semana em cada um, mas em El Quadron passa apenas algumas horas do dia porque a demanda é pequena. Nestes povoados há apenas consultórios cuja arquitetura varia e pelo que pude apurar, depende da dedicação do alcalde (prefeito), embora a res- 
ponsabilidade pela organização da saúde, em todos os níveis, seja da província. A província de Madrid é dividida em 12 áreas, cada uma abrangendo uma parte da capital e uma parte da área rural. Estamos falando da área 5 de atenção primária, com um total de mais de meio milhão de habitantes. Vale ressaltar que na Espanha as províncias como Madrid são chamadas «Comunidades Autônomas» pois têm de fato muita ingerência sobre a organização dos sistemas de saúde, educação, segurança, etc... No total, na Espanha, existem 17 Comunidades Autônomas, o que faz dela uma nação de organização federal.

O centro de saúde fica na cidade de Buitrago de Lozoya (2 mil habitantes), onde reside Juan e sua esposa Mercedes. O material é estocado ali e as equipes que atendem os 41 povoados (com um total de 5.000 habitantes) da região sempre se reúnem lá antes de irem para as áreas rurais. São 8 médicos e 5 enfermeiros, então podemos classificar como «equipes abertas». A divisão dos povoados para os médicos não segue a mesma dos enfermeiros e ambos podem ir ou não no mesmo dia para os consultórios avançados. No caso do Juan isto raramente acontece. Juan sempre começa o dia de trabalho com uma conversa informal em que pergunta aos que ficaram de plantão à noite no centro de saúde sobre alguma ocorrência com os pacientes dos povoados dos quais é responsável. O trabalho do médico geral na Comunidade Autônoma de Madrid é, em geral, das 8 às 15 horas (embora em Buitrago façam das 9 às 16), no turno da manhã e de 14 a 21 horas no turno da tarde. Depois há plantões realizados em duplas (médico geral e enfermeiros). Juan sempre procura ir aos povoados pelo menos uma vez por mês à tarde e à noite para dar atenção especial aos trabalhadores e estudantes, que têm problemas de acessibilidade no horário matutino. Os pontos que mais chamaram a atenção nos dias em que acompanhei a rotina deste admirável ser humano passo a destacar abaixo.

O primeiro e, talvez, mais impressionante ponto, é com relação a polivalência de Don Juan (alguns pacientes o chamam assim). Leva material cirúrgico do centro de saúde para os consultórios, faz pequenas cirurgias, atende todas as demandas, faz visitas domiciliares nas fazendas da região, atende o celular que fornece para pacientes em estado terminal e se o paciente quer, mesmo após ter sido orientado dos riscos, o próprio Juan ministra vacinas. Se alguma criança quer vacinar, não espera o dia do enfermeiro e a faz na hora. O mesmo ocorre para qualquer medicação intramuscular ou endovenosa. Também faz curativos em úlceras crônicas. Claro, por tudo isso se queixa da inércia dos enfermeiros que deveriam colaborar mais com os cuidados aos pacientes. Acha que o médico deveria ficar com as coisas mais difíceis como pacientes descompensados ou com dificuldade de adesão ao tratamento. Não utiliza prontuário eletrônico (é um dos poucos de toda província de Madrid) porque defende a autonomia do médico e o sigilo do paciente. Aceitaria usar se apenas algumas informações mínimas fossem divididas com outros profissionais. Utilizou para explicar um exemplo extremado, mas plenamente plausível: «se um paciente diz que está sofrendo porque descobriu que sua esposa é prostituta, o dermatologista não precisa saber disso». De fato, os médicos também circulam na sociedade e podem ter uma relação com determinados pacientes que fazem com que a informação que é relatada para cada profissional tenha uma «edição» diferente. Os prontuários precisariam ser mais favoráveis a atividade do médico geral, pois, como diz, os informatas sempre prometem que «em dez anos não será possível trabalhar sem prontuário eletrônico». Os 10 anos sempre passam e nada ocorre. Diz que escuta isso há pelo menos quatro décadas (teve uma bolsa da IBM para o desenvolvimento da informática médica em 1969). Ele ainda lava o material cirúrgico que usou e carrega ao centro de saúde para ser esterilizado. Se fez alguma exérese, coloca a peça anatômica no formol e também a leva ao centro de saúde para que seja encaminhada ao laboratório. Ele mesmo prepara o frasco com o formol e sempre traz do centro de saúde em Buitrago para que nunca falte. Em um dos dias que o acompanhei realizou uma exérese de uma lesão em um idoso que usava anticoagulante por fibrilação atrial. Juan está acostumado a este tipo de procedimento. Como era de se esperar o paciente sangrou muito após a pequena cirurgia e, como a lesão era na região lombo-sacra, seria difícil um curativo verdadeiramente compressivo. Por isso, ligou quando chegou em casa no início da tarde ao paciente. Como ainda sangrava bastante, Juan voltou ao povoado e refez os pontos bem como fez a compressão ele mesmo por quase uma hora até que estancasse o sangramento e o problema estivesse so- 
lucionado ali mesmo no povoado. O hospital mais próximo onde estão os especialistas fica a $70 \mathrm{~km}$ de distância. Neste retorno ao povoado os vizinhos vieram ao consultório e queriam entrar na sala para saber melhor o que estava acontecendo gerando grande expectativa nas pessoas daquela área pacata e rural. Foi o acontecimento do dia. Depois, à noite, Juan voltou a ligar para o paciente e sua esposa para saber se estava tudo bem. Falou também com o filho do paciente em Madrid para tranqüilizá-lo. Após 15 dias quando já estava no Brasil, Juan me mandou um correio eletrônico relatando que o resultado do anátomo patológico foi «carcinoma basocelular superficial múltiplo com áreas de carcinoma basocelular infiltrante de mecanismo expansivo respeitando os bordos cirúrgicos». Ou seja, trata-se de um médico rural de altíssima resolutividade.

Para toda esta polivalência é preciso material adequado. Uma parte o governo providencia e Juan leva do centro de saúde até os consultórios nos povoados em que atende e a outra Juan carrega em sua «valise tecnológica» (possuiu uma «cabas», a típica maleta de médico para atender os pacientes a domicílio). O congelante a base de éter para criocirurgias em verrugas e hiperqueratoses, a morfina para analgesias em pacientes oncológicos e o cloreto de etila em spray para anestesias rápidas em drenagens de abscesso, por exemplo, o governo providencia. Já o glucagon para hipoglicemias, a infusão retal de benzodiazepínico para convulsões e a microespátula com imã para retirada de corpo estranho ocular, Juan carrega em sua recheada maleta. Embora utilize alguns produtos farmacêuticos no dia a dia, nunca recebe seus representantes e é fundador e militante de iniciativas como «No Gracias» ${ }^{1} \mathrm{e}$ «HealthySkepticism». ${ }^{2}$ Os consultórios que atende em geral são adequados sendo que dois dos três são novos. Há geladeiras para estocar uma pequena quantidade de vacina bem como oto e oftalmoscópios elétricos (de parede). Nos povoados também há creches ou «casa de niños» que parecem muito saudáveis e Juan sempre as visita de jaleco e pompa de médico rural. No centro de saúde de Buitrago fazem coleta de sangue dois dias por semana para enviar aos laboratórios que antes eram públicos mas estão sendo terceirizados.

A segunda característica que chama a atenção é o uso da medicina baseada em evidência. Juan não segue a prática de solicitar mamografia ou colesterol de rotina ou obrigar todos os tabagistas a pararem de fumar. De fato não pratica a "pornoprevenção». ${ }^{3}$ Sempre avalia individualmente os riscos e utiliza todos os atributos próprios da atenção primária à saúde. Não há agendamento e o acesso é livre. Tem prioridade apenas trabalhadores, crianças (pois os pais têm que ir trabalhar) e gestantes. Assim a sala de espera passa por um «auto controle» e quem não precisa no momento volta uma hora que esteja mais vazia. Mas nunca enche pois há uma dinâmica: são de 30 a 50 pacientes por dia (em uma semana chega a atender $10 \%$ da população de um povoado) e as consultas têm em média 5 a 10 minutos mas podem demorar 20 no caso de um procedimento cirúrgico ou uma consulta que chama de "sagrada» (diagnóstico de doença que não tem cura, ideação suicida, paciente que perdeu algum parente recentemente, gestantes, paciente que chora na consulta, etc...). ${ }^{4}$ Desta forma, alguns pacientes podem consultar até 52 vezes por ano. Nestes três dias presenciei pacientes que foram 2 ou 3 vezes ao dia no consultório por serem hiperutilizadores (por exemplo, uma paciente com transtorno de personalidade) ou por estarem com agudização de algum problema crônico (como uma crise alérgica).Vale comentar que não há limitação alguma mesmo para os hiperutilizadores. Portanto, 52 vezes em um ano, são praticamente 520 minutos ou quase 10 horas com El Doctor Juan. Na Espanha o número de consultas médicas por habitante/ ano é de 9,5 vezes, ou seja, o dobro do Reino Unido e $50 \%$ vezes mais que na França. No Brasil, segundo dados do Prograb, ${ }^{5}$ são 1,4 vezes ao ano. Talvez tenha influência neste excesso de utilização o fato da Espanha contar com sistema de saúde com cobertura universal e $100 \%$ da população ter de fato este direito (imigrantes ilegais incluídos). Na consulta de Juan os pacientes que realmente necessitam são referenciados (para emergência ou especialista focal), mas são raros estes casos. Como não faz uma prática «protocolizada» as consultas para verificar exames de rotina não são freqüentes. Quando questionado se não se cansa de «sentar, levantar e levar e receber até a porta dando a mão aos pacientes de 30 a 50 vezes ao dia" Juan diz que não, que é um exercício e que se sente saudável o suficiente para fazer esta atividade. Tampouco se cansa de lavar as mãos após cada exame físico, hábito que sempre praticou como forma de higiene e segurança do trabalho para si e para seus pacientes. 
Juan se queixa de quem se queixa. Por várias vezes me pareceu que se conforma menos com isso do que com os problemas do governo e da organização da atenção primária, motivo das queixas. Por exemplo, para cada caixa de medicamento, precisa uma receita. Se o paciente necessita de duas caixas de AAS e uma de sinvastatina são três receitas distintas. Outro exemplo é atestado médico (ou baixa laboral). O médico de família pode atestar por até um ano, mas a cada semana o paciente precisa renovar a baixa com novo papel. Estes são exemplos de como a burocracia aumenta a carga de trabalho, mas Juan reclama mais dos que utilizam estes problemas como desculpa para não trabalhar do que dos problemas em si. Seria fácil se recusar a fazer visitas domiciliares em fazendas longínquas já que não há praticamente auxílio combustível ou não fazer procedimento cirúrgico se não tivesse quem lavasse o material e levasse ao centro de saúde de Buitrago. Pude acompanhar Juan em uma visita a uma família de empregados de uma fazenda com acesso muito precário e bastante distante da cidade. Era uma senhora com dificuldade de locomoção que era cuidada pela filha. Se queixava de mal estar epigástrico e Juan fez algumas alterações nas medicações. A consulta foi bastante completa embora tenha durado 15 minutos. Logo seguiu para o consultório. Neste dia ele fez a visita domiciliar as 8:30 da manhã, antes das consultas regulares, pois a família tinha requisitado. O centro de saúde de Buitrago tem três veículos sendo um quatro por quatro e Juan poderia solicitá-los para as visitas, mas entraria em uma burocracia e atrapalharia sua atenção aos pacientes cuja demanda dificilmente se encaixa na «agenda do carro». No inverno há neve abundante na região e o acesso aos povoados fica difícil. Em cada vilarejo (mesmo nos menores) o governo construiu um heliponto em caso de isolamento da estrada.

Juan também não seria obrigado a fornecer o telefone celular para os parentes de pacientes terminais que podem chamá-lo a qualquer dia ou hora e não há remuneração para isso. Não raro fornece também seu email para que os pacientes possam «continuar a consulta». Mas toda esta dedicação tem pelo menos uma recompensa. Juan sempre ganha presentes. Às vezes são flores e outras produtos da região que variam conforme a época. Pude presenciar Juan ganhando algumas caixas de ovos. As flores ele arranja em cima da mesa de consulta. Nos três consultórios que atende tem flores enfeitando a mesa para tornar o ambiente mais agradável. O bloco de receitas nunca está à vista no início da consulta e na sala de espera tem à disposição um texto com um pouco da história do profissional que atende ali entitulado "Consulta del Doctor», e outro sobre a Gripe A que tem como subtítulo "paciência y tranquilidad». O texto sobre sua história pessoal, cuja cópia oferece a cada paciente novo, fala de sua família, sua trajetória profissional e também de como é a consulta com um médico geral. Cita aforismos como «não há enfermidades, apenas enfermos». Quando perguntado porque aquele texto, ele explica: «vamos perguntar várias coisas aos pacientes, é justo que saibam algumas de nós». De fato muitas consultas são «personalizadas» e os pacientes trazem fotos dos parentes que Juan não vê há algum tempo além de cartões postais. Juan usa jaleco com todos os pacientes pois diz que a consulta tem que ser «suja». No final de um período, invariavelmente fez algumas análises de urina com a fita e algum procedimento cirúrgico. Tudo sem agendamento. Atende a todos e a todas as demandas que aparecem no mesmo dia. Digo que iriam acusá-lo no Brasil de estar fazendo pronto atendimento e que aqui em geral se exige 20 minutos por paciente, há consulta programada para hipertensos e idosos mas é comum uma pessoa que não pertence a um "grupo prioritário» não conseguir espaço pois em geral os profissionais atendem 12 a 16 em um período. Don Juan faz uma cara de lamento e diz apenas: «isto não é medicina geral, isto não é saúde pública».

Juan vive com a esposa Mercedes Pérez Fernández, também médica geral rural, em uma agradável casa de 80 metros quadrados na beira do rio Lozoya, que corta Buitrago. Parece um lugar que normalmente escolheríamos para passar férias ou a lua de mel. Saem para o trabalho às 8 e voltam entre 14 e 15 horas. Sim, Juan não para das 8 às 15. Apenas para tomar água e ir rapidamente ao banheiro. À tarde o casal faz um lanche e depois descansa um pouco. A janta é a refeição mais importante do dia para eles. Juan sempre vai para o computador no final da tarde e início da noite e também das 4:30 às 7 da manhã. Confere inúmeras listas de discussão de médicos de família russos, portugueses, espanhóis, canadenses, ingleses, brasileiros, etc. Acredita no poder da internet como forma de capacitação per- 
manente e troca de informações. Em uma das festas do povoado uma parente de uma paciente que não trabalha na área da saúde, se aproximou para relatar que recebeu por e-mail o texto de autoria do Juan sobre Gripe A que recomendava paciência e tranqüilidade. Ele acha que atualmente as listas de discussão estão mais fortes que as revistas científicas na disseminação de informações e conseguem, inclusive, proezas como desmascarar em tempo recorde um alerta exagerado como ocorreu com a gripe $\mathrm{A}$.

O soldo de um médico espanhol não passa muito dos 3 mil euros e um apartamento de classe média em Madrid para alugar custa aproximadamente $1000 \mathrm{eu}-$ ros. Isto faz do médico na Espanha um cidadão comum de classe média que muitas vezes precisa se casar com um(a) outro(a) médico(a) para ter uma renda melhor. Para Juan nem isso serve de desculpa para reclamar do trabalho pesado na atenção primária. Se aposentará em breve com sua esposa e o soldo cairá bastante (na Espanha as aposentadorias têm o teto de 2300 euros pelo sistema de previdência nacional) mas isto também não é motivo para se queixar da vida que teve. Pelo contrário, tem quatro filhos educados e autônomos e gosta do que faz. Respira e transpira atenção primária na sua forma plena e bela, que é a científica. Quando pergunto como faz para ter tempo para tudo a resposta é simples e igualmente «científica»: basta não ter televisão e não tomar café. Juan Javier Gérvas Camacho é uma fonte de inspiração.

No penúltimo dia da visita fomos (Mercedes, Juan e eu) à cidade de Madrid para o seminário de inovação. Don Juan tem uma capacidade de aglutinar pessoas interessantes com histórias de vida muito diferentes mas alguma coisa em comum: a vontade de pensar com as próprias pernas. O seminário é mágico. Parece uma tourada. Duas semanas antes as caixas de e-mails são alimentadas com os textos dos três desafiantes. Os participantes passam a municiar a peleja com uma série de textos de excelente qualidade. O tema da ocasião era irracionalidade diagnóstica do médico e do paciente. Nas vésperas do grande dia, Don Juan envia uma mensagem com as coordenados do evento. Neste momento parece um encontro clandestino, de comunistas que querem abater Franco. O encontro desta vez será na Cervejaria Alemã, no centro de Madrid. Pontualmente na hora marcada Juan e sua esposa, Merce- des, se sentam próximos a janela. Os guerrilheiros começam a chegar e se apresentar. Vem gente de todos os cantos da Espanha, além de representantes da Alemanha, Portugal, Chile, Argentina e, eu, do Brasil. Parece que as pessoas já se conhecem há muitos anos.

Exatamente na hora marcada para acabar a confraternização todos se retiram para seus aposentos. No dia seguinte ocorreu o seminário na sede da Organização Médica Colegial ou OMC (correspondente a Associação Médica Brasileira) e às 9 em ponto os desafiados começaram a expor seus pontos de vista, levando em conta o debate prévio on line e os textos comentados. Às 11:30 acabaram as exposições. Todos foram a um café próximo a OMC, um dos financiadores do Seminário juntamente com o Ministério da Saúde espanhol. Às 12 horas em ponto recomeçou o debate e todos tiveram oportunidade de fazer uma breve exposição. Juan não permite que ninguém fuja do tema e do foco. Também não deixa passar muito dos 3 minutos por pessoa e, mais importante, não deixa que a discussão deixe de ser científica. Às 15 em ponto terminou a peleja com material suficiente para alguns artigos científicos de altíssima qualidade. Todos fomos a um restaurante para mais uma confraternização. O dia, a semana, o ano e, quiçá, a vida está ganha e plena por pelo menos um momento. A preparação para o próximo seminário de inovação continuaria na semana seguinte por email. Juan novamente dá o tom e o foco. No último dia, voltamos a Buitrago para me despedir da cidade. Fomos a Biblioteca (inimaginável para uma cidade de 2000 habitantes no Brasil) e ao Museu Picasso. Sim, na pequena cidade há um museu com acervo doado pelo cabelereiro do Picasso, que era natural de Buitrago, mas viveu exilado na França, assim como o pintor, por causa da ditadura na Espanha. Embora tenha obras de grande valor, a família do cabelereiro doou o acervo para a cidade natal dele e o mesmo se encontra conservado e exposto gratuitamente (fato também inimaginável para o Brasil).

A estadia em Buitrago foi inesquecível. Fiquei hospedado como convidado no Hotel Los Canchos que é simples por fora mas absolutamente completo por dentro. Todo reformado recentemente é extremamente funcional com um quarto muito aconchegante e internet bastante rápida inclusa na diária. O Hotel Los Canchos está na Vila de Buitrago, na parte que fica dentro 
das muralhas. O povoado fora saqueado e ardeu queimado pelas tropas de Napoleão quando da sua retirada da Espanha em 1808. Ficou conservado o recinto envolto em muralhas do século XI a XV, que é parte do patrimônio histórico nacional. Também ficaram intactos restos do castelo e do hospital do século XV e se mantém a Igreja da Antigua, da mesma data. A importância de Buitrago vem do controle do portal de Somosierra que fica na montanha e que comunica as duas metades da Espanha (sul e norte). Por causa dele Buitrago foi importante na história tendo sido citada por Tito Livio no século I d.C.

Os lanches e jantares na companhia de Juan e Mercedes, as conversas na varanda voltada para o jardim ainda florido apesar do outono e o leito do rio formado de paredes rochosas foram momentos memoráveis. O tema era em geral atenção primária e saúde pública mas também criação dos filhos, planejamento da vida, novos desafios e como agir diante deles. Foram sete dias que valeram por muitos, impossível precisar quantos. O tempo, como pintava Dali, é algo fluido, muito difícil de mensurar. Aqueles momentos estão vivos e serão vividos por muitos e muitos anos.

Obs: Para saber mais sobre os seminários de inova- ção, acesse http://www.fcs.es. Para saber mais sobre os trabalhos científicos de Juan Gérvas, acesse http://:www.equipocesca.org

Conflito de interesse: o autor declara que o único conflito de interesse é uma admiração "não científica" pelo personagem deste texto.

\section{REFERÊNCIAS BIBLIOGRÁFICAS}

1. No Gracias. Disponível em: http://www.nogracias.eu/v_portal/apartados/pl_basica.asp?te=2309 [acedido em 05/02/2010].

2. Healthy Skepticism. Disponível em: http://www.healthyskepticism.org/ [acedido em 05/02/2010].

3. Verdú V. Pornoprevención. El País, 3 de mayo de 2003 (n 9.350); p. 29.

4. Gérvas J, Perez Fernández M, Gutiérrez Parres B. Consultas sagradas: serenidad en el apresuramiento. Aten Primaria 2009 ene; 41 (1): 41-4.

5. Brasil. Secretaria de Atenção à Saúde. Departamento de Atenção Básica. Prograb: Programação de gestão por resultados / Secretaria de Atenção à Saúde, Departamento de Atenção Básica. Brasília: Ministério da Saúde; 2006.

\section{ENDEREÇO PARA CORRESPONDÊNCIA}

Gustavo Gusso

E-mail: gusso.gustavo@gmail.com

Recebido em 26/12/2009

Aceite para publicação em 26/02/2010

\section{ABSTRACT}

\section{ONE WEEK IN MADRID: CAPITAL AND RURAL}

A day by day week, report of a Brazilian general practitioner experience with a Spanish rural doctor, called Juan Gervas. This Spanish doctor living in a rural area is the author of several scientific papers published in very different scientific journals, expressing scepticism regarding pharmaceutical industry and the excess of preventive care in primary health care. Recently he has been one, of the few those, who have claimed against the fault danger of the A flew (H1N1).

Keywords: Rural Medicine; Family Medicine; Prevention; Primary Health Care. 